\title{
A COMPARISON OF TRANSPORTATION NETWORK RESILIENCE UNDER SIMULATED SYSTEM OPTIMUM AND USER EQUILIBRIUM CONDITIONS
}

\author{
Pamela M. Murray-Tuite \\ Dept. of Civil and Environmental Engineering \\ Virginia Tech \\ 7054 Haycock Road \\ Falls Church, VA 22043, U.S.A.
}

\begin{abstract}
Resilience is a characteristic that indicates system performance under unusual conditions, recovery speed, and the amount of outside assistance required for restoration to its original functional state. Resilience is important for daily events, such as vehicle crashes, and more extreme events, such as hurricanes and terrorist attacks. Transportation resilience has ten dimensions: redundancy, diversity, efficiency, autonomous components, strength, collaboration, adaptability, mobility, safety, and the ability to recover quickly. This paper examines the influence of the system optimal and user equilibrium traffic assignments on the last four dimensions. No widely accepted measurement of resilience is available for transportation systems; this paper presents multiple metrics for the four examined contributing components that will aid future development of a single measure of resilience. An application of these measures to a test network found that user equilibrium results in better adaptability and safety while system optimum yields better mobility and faster recovery.
\end{abstract}

\section{INTRODUCTION}

Predicting transportation system performance during unusual conditions is an extremely challenging problem; however, such predictions are critical to planning for emergency situations. Because the vulnerability of technological and social systems cannot be completely determined (Foster 1997), system performance predictions must go beyond risk assessments and consider resilience. In general terms, resilience is the ability of a community or system to adapt to hazards so as to maintain an acceptable level of service (Subcommittee on Disaster Reduction 2005).

A resilient transportation system has ten properties: redundancy, diversity, efficiency, autonomous components, strength, adaptability, collaboration, (Godschalk 2002), mobility (Victoria Transport Policy Institute 2005), safety, and the ability to recover quickly. Godschalk
(2002) defines the first six terms as follows. Redundancy indicates that multiple components serve the same function. Diversity means that the components are functionally different. Efficiency indicates input-output ratio optimization. Autonomous components have the ability to operate independently. Strength indicates the system's ability to withstand an event. Adaptability implies that the system is flexible and elements are capable of learning from past experience (Godschalk 2002). The remaining terms are defined as follows. Collaboration indicates that information and resources are shared among components or stakeholders. Particularly pertinent to the transportation system, mobility indicates that travelers are able to reach their chosen destinations at an acceptable level of service. Safety suggests that the system does not harm its users or unduly expose them to hazards. Finally, the ability to recovery quickly means that an acceptable level of service can be restored rapidly and with minimal outside assistance after an event occurs. The complexity of each of these ten dimensions and their interactions makes it difficult to obtain a comprehensive measure of resilience.

The use of multiple metrics and simulation provides a promising approach for addressing the complexity of resilience. This paper addresses the measurement of transportation resilience through the evaluation of four of its dimensions and is the first to examine the impacts of traffic assignment on resilience. This work uses simulation to compare the user equilibrium and system optimum traffic assignments with respect to adaptability, safety, mobility, and recovery.

The remainder of this paper is divided into five sections. Section 2 provides a summary of the literature related to resilience, including perspectives from fields other than transportation. Section 3 describes the specific problem addressed in this work. Section 4 provides the methodology and defines the measures used to assess transportation resilience. Section 5 discusses the results of the methodology applied to a sample network. Finally, section 6 summarizes this work and provides future directions. 


\section{BACKGROUND}

Resilience has been explored from the community, water, power, and communication perspectives, but transportation has been addressed only to a limited degree. This section focuses on previous works from different fields that proposed quantitative measures of resilience.

At a high level, Mileti (1999) suggests community resilience measurements in terms of extraordinary damage, productivity losses, quality of life, and quantities of assistance required from outside the immediate community. Infrastructure analyses are more granular and specific than the community level. For example, Chang and Chamberlin (2005) measure resilience in terms of economic losses due to the failure of water and power systems. Shinozuka et al (2005) evaluate the power supply for each service area, households without power, speed and efficiency for repair and restoration, and employment loss. Like Mileti's and this last work, the current study uses several metrics.

Dolev et al (c. 2004) also propose multiple metrics, although their work is focused Internet connectivity and not on the effects of its loss. Connectivity is an important element in assessing transportation resilience, however the human element of transportation systems prohibits the direct application of Dolev's metrics. Furthermore, the Internet is connected according to a scale-free power law (Cohen et al 2000), whereas transportation networks are specifically designed with a limited number of connections at each node.

Buckle (2005) provides a loss model approach for any infrastructure, including power, communications, and transportation. Buckle's approach involves measuring the percentage decrease in infrastructure quality, residual capacity, and recovery time. In an associated paper, Werner et al (2005) examine transportation resilience, measured in terms of travel time increases after an earthquake.

Travel time and capacity are also factors in MurrayTuite and Mahmassani's (2004) work, in which they develop a disruption index for transportation networks. Although not explicitly stated as such, this index combines the resilience elements of redundancy, diversity, and mobility. This index is among the first to combine multiple resilience dimensions into one measure. However, additional resilience dimensions and their interactions need to be thoroughly studied before integration with Murray-Tuite and Mahmassani's disruption index. The current paper initiates an exploration of four dimensions, only one of which overlaps with the disruption index, and this dimension is measured differently.

Like Murray-Tuite and Mahmassani (2004) and Buckle (2005), Morlok and Chang (2004) evaluate the amount of unused capacity in a network. Morlok and Chang measure capacity flexibility through changes in demand, including traffic quantities, commodity mixes, and flow patterns. However, their work focused freight on rail systems, which have limited infrastructure and fewer routing choices compared to the road transportation system.

As noted by Allenby and Fink (2005), each system faces a unique set of challenges. The unique challenges, combined with differences among infrastructures and their flows, lead to the inability to directly transfer analysis techniques and measures across fields. However, some of the measures, such as travel time, recovery time, and level of service, are applicable. These measures, in addition to several others, are used in this study to evaluate the impact of traffic assignment on four resilience dimensions. All of the previous resilience studies lack consideration of traffic assignment, creating a gap that is addressed by this paper.

\section{PROBLEM DESCRIPTION}

This work compares the system optimum (SO) and user equilibrium (UE) traffic assignments with respect to their effects on adaptability, safety, mobility, and recovery. The SO assignment minimizes the travel time for all vehicles in the network, while the UE assignment minimizes travel time for individuals. The vehicles travel on a transportation network $G(N, A)$ consisting of a set of nodes $\mathrm{N}$ and directed $\operatorname{arcs} \mathrm{A}$. Each link $a$ has a capacity $c_{a}$ and a posted speed limit $u_{a}$.

A man-made event is envisioned which necessitates an evacuation of the network's residents during the evening. In addition to the town's residents, some evacuating through traffic uses elements of the network. All evacuating vehicles are assigned one of two destination zones, with the majority of each origin zone's traffic traveling to the nearest destination zone. In addition to this traffic, response vehicles, such as police, fire, and medical service vehicles, travel among the residential zones. The measurement of adaptability, safety, mobility, and recovery includes all of this traffic. The notation associated with the measurements is summarized below:

$G(\mathrm{~N}, \mathrm{~A})$ : graph denoting the transportation network consisting of a set of nodes $\mathrm{N}$ and directed arcs A

$\mathrm{A}_{1}{ }^{\mathrm{rs}}$ : set of directed special use arcs connecting origin node $r$ with destination node $s$

$a$ : index of the set A

$b$ : $\quad$ speed threshold index

$c_{a}$ : $\quad$ capacity of link $a$

$D: \quad$ total vehicle miles traveled

$d_{i}$ : $\quad$ queue length $i$ threshold

$E$ : $\quad$ evacuation time

$H$ : number of vehicles exposed to hazards

$L_{a}$ : queue length on directed arc $a$

$m_{l}$ : percentage of eligible vehicles that use special lanes

$m_{2}: \quad$ expected fatalities due to traffic incidents 
$p_{w}{ }^{r s}$ : path of vehicle $w$ from origin node $r$ to destination node $s$

$q$ : $\quad$ average queuing time per vehicle

$r$ : $\quad$ origin node index

$R: \quad$ origin zone index

$s: \quad$ destination node index

$S: \quad$ destination zone index

$t_{a}^{l}$ : time point at which the queue length on link $a$ returns to a predetermined range

$t_{a}{ }^{u}$ : time at which the speed on link $a$ returns to or exceeds the posted speed limit

$t_{a}{ }^{v}$ : time at which the volume/capacity ratio on link $a$ returns to a pre-specified range

$U_{a b}$ : amount of time link $a$ offers average speeds lower than a threshold $b$ of its posted speed limit

$u_{a}: \quad$ posted speed limit

$v_{a}: \quad$ volume of traffic on link $a$

$w$ : vehicle index

$\phi_{p}$ : binary variable taking the value 1 if path $p$ contains one or more special use lanes and 0 otherwise

$\lambda$ : fatality or incident rate

$\mu^{R S}$ : average travel time between zones $R$ and $S$ for response vehicles

$\theta^{r s}$ : binary variable taking the value 1 if a path exists between origin node $r$ and destination node $s$ that includes a special use lane and 0 otherwise

$\sigma^{R S}: \quad$ standard deviation of travel time between zones $R$ and $S$ for response vehicles.

\section{METHODOLOGY}

In this study, the traffic assignment-simulation methodology DYNASMART-P generates SO and UE traffic assignments for a test network (discussed in Section 5). The output of the simulations is then used to evaluate adaptability, safety, mobility, and recovery according to the measures discussed below.

\subsection{Adaptability}

A network's adaptability to an event or its impacts can be measured through atypical uses of infrastructure, transportation modes, and demand management. This work considers atypical uses of infrastructure. For any $\operatorname{arcs}\left(\mathrm{A}_{1}{ }^{\mathrm{rs}}\right)$ connecting origin node $r$ with destination node $s$ not normally used for general traffic, calculate the percentage of vehicles using these lanes, as in Equation (1). Note that special use lanes (such as high-occupancy vehicle) can be modeled as links separate from general use lanes.

$$
m_{1}=\frac{\sum_{w} \theta^{r s} \phi_{p} p_{w}^{r s}}{\sum_{w} \theta^{r s} p_{w}^{r s}} \times 100
$$

where

$p_{w}{ }^{r s}$ is the path of vehicle $w$ going from origin node $r$ to destination node $s$,

$\phi_{p}$ is a binary variable taking the value 1 if path $p$ contains one or more special use lanes and 0 otherwise,

$\theta^{r s}$ is a binary variable taking the value 1 if a path exists between origin node $r$ and destination node $s$ that includes a special use lane and 0 otherwise.

\subsection{Safety}

Safety, in the traditional surface transportation sense, often refers to the number of traffic incidents that occur along a given road, or a similar measure. Since link level data may be difficult to obtain, a rough estimate $\left(m_{2}=D \lambda\right)$ can be derived by multiplying the total vehicle miles traveled $(D)$ by the fatality or incident rate $(\lambda)$, publicly available from the National Highway Traffic Safety Administration (NHTSA). The units of the rate are often fatalities per million vehicle miles traveled. NHTSA's statistics are calculated for normal traffic conditions, but no evacuation scenario statistics are available at this time (additional research is needed to determine the transferability of the fatality rates).

In situations where resilience is critical, a second especially relevant safety measure is the number of vehicles $(H)$ exposed to hazards. For example, during hurricanes, this measure can be the number of vehicles who pass by lakes and rivers prone to flooding. Under deliberate attacks, $H$ could be the number of vehicles driving by secondary targets.

\subsection{Mobility}

In this work, mobility is measured in six different ways. First is the amount of time $E$ required to evacuate a town's residents. Second is the ability of response vehicles, such as ambulances, to travel from one zone to another; this ability is measured by the average travel time $\mu^{R S}$ between zones $R$ and $S$ and the standard deviation $\sigma^{R S}$. Third is the queue length $L_{a}$ on directed arc $a$, which can be evaluated at various length thresholds $d_{i}$. Fourth is the average queuing time $q$ per vehicle. Fifth is the amount of time $\left(U_{a}\right)$ link $a$ offers average speeds lower than a threshold $b$ of its posted speed limit $\left(u_{a}\right)$. The final measure is the volume to capacity $(v / c)_{a}$ for each link $a$. 


\subsection{Recovery}

Measures of recovery are case specific and depend on whether infrastructure is damaged by the event. If infrastructure is damaged, recovery can be measured by the amount of time, money, and outside assistance required to restore connectivity at an acceptable level of service, the thresholds of which may also be situation dependent. In the case where no infrastructure damage occurs, as in the application in Section 5, recovery is measured by the amount of time required to alleviate congestion. Corresponding to the third, fifth, and sixth measures of mobility in Section 4.3, three measures of recovery are used in this study. Let $t_{a}^{l}$ be the time point at which the queue length on link $a$ returns to a predetermined range. Let $t_{a}{ }^{u}$ be the time at which the speed on link $a$ returns to or exceeds the posted speed limit. Finally, let $t_{a}{ }^{v}$ be the time at which the volume/capacity ratio on link $a$ returns to a pre-specified range.

\section{APPLICATION AND RESULTS}

Suppose an intentional, man-made event occurs in the Washington, D.C. area that requires an evacuation from east to west in the late evening. The resilience of a test network, based on a simplified version of Reston, Virginia (a western suburb of Washington, D.C.) is examined using the methodology discussed in Section 4. The selection of this network is based on the flexibility offered by both separated airport express lanes and high occupancy vehicle (HOV) lanes, whose restrictions are in affect during the rush period in the peak direction. Figure 1 shows the network, consisting of 147 nodes and 354 links. For the purposes of this study, the network is divided into 14 zones. Two of these zones, consisting of the two rightmost nodes, are strictly for generating through traffic. Two others, consisting of the northernmost and westernmost nodes, represent destination zones for all traffic except response vehicles.

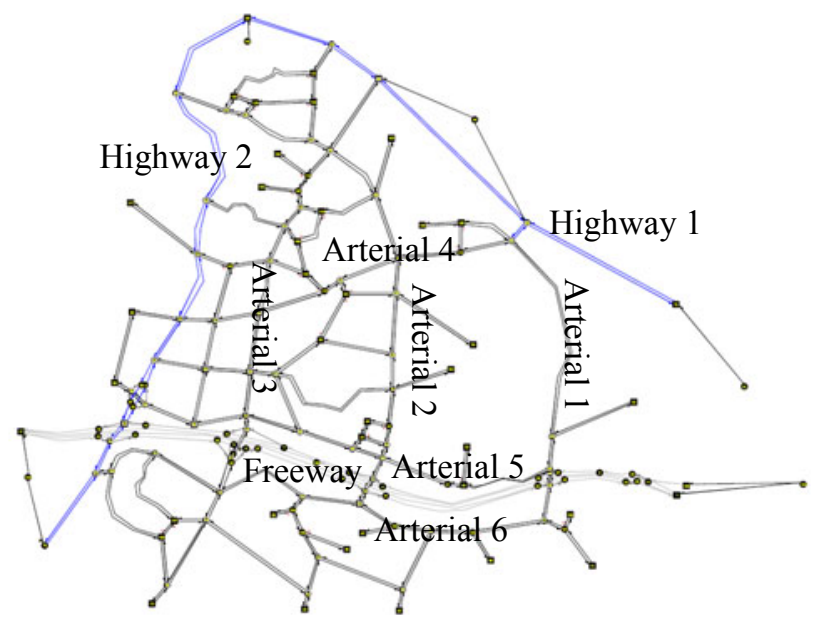

Figure 1: Test Network
According to the U.S. Census Bureau (2000), Reston has a total population of 56,407 , of which 33,333 are employed. Based on the 25,472 workers who commute by driving alone and the assumption that half of the remaining 7,861 workers have vehicles, the number of vehicles that would be evacuating the town is approximately 29,403 .

Reston has a considerable amount of through traffic, particularly along the Dulles Toll Road, which is shown as the major east-west freeway in Figure 1, and Route 7, which is the northwest - southeast road on the top right of Figure 1 (labeled Highway 1). A moderate amount of through traffic (approximately 12,700 vehicles) is included in the simulation.

Using DYNASMART-P, the through, residential, and response vehicle traffic is assigned first according to the system optimum and second according to the user equilibrium. The entire planning horizon is 480 minutes. Through vehicles begin at time 0 and have the first 30 minutes of the simulation to establish background traffic. The Reston vehicles are generated over the next half hour, along with response vehicles and additional through traffic. Through vehicles continue to enter the network for an additional 30 minutes. Response vehicles enter the network from time 30 until 210. The results of these simulations are then used to evaluate the resilience components adaptability, safety, mobility, and recovery. The resilience evaluation follows in the subsections below, but first, Table 1 presents high level results for all vehicles in the simulation. Over all vehicles, SO yields a slightly longer average distance, shorter travel time, and shorter average stopped time. However, these aggregate results are too close to draw any solid conclusions about resilience. More detailed results are presented in the following subsections.

Table 1: Averages for All Simulated Vehicles

\begin{tabular}{lcc}
\hline & SO & UE \\
\hline Average Distance (mi) & 7.719 & 7.690 \\
Average Travel Time (min) & 54.254 & 54.496 \\
Average Stop Time (min) & 36.190 & 36.747 \\
\hline
\end{tabular}

\subsection{Adaptability}

Reston has two types of special lanes that require no infrastructure modifications or additional instructions to use: the HOV and airport express lanes. Contraflow lanes are not considered in this scenario. Due to the evacuation, HOV lanes are open to all travelers and not considered special. Within the boundaries of the network shown in Figure 1, the airport express lanes are only available to through traffic. Under the SO assignment, $49.74 \%$ of the vehicles that could use these express lanes for evacuation purposes did so. For the UE case, $53.40 \%$ of the eligible vehicles used these lanes, indicating that the UE traffic assignment exploits the system adaptability to a greater degree. 


\subsection{Safety}

The first measure of safety is related to traffic incidents. Virginia's 2003 fatality rate is 1.23 per million vehicle miles traveled (National Center for Statistics \& Analysis c. 2005). Under SO conditions, a total of $316,148.34$ miles were traveled, yielding a value of 0.389 for $m_{2}$. Under the UE assignment, a total of 314,961.12 miles were traveled, yielding a safety measure of 0.387 . For this measure, a lower value indicates a better score, thus UE gives a slightly more resilient situation for this measure.

The second safety measure is related to the number of vehicles exposed to hazards. Since the scenario under consideration is related to an intentional man-made event, $H$ is measured as the number of vehicles passing potential secondary targets. For this study, the likely secondary targets are contained within Reston's town center, which includes shops, mid-high-rise office space, and mid-high-rise apartments/ condominiums. This area is contained within zone 10 and shown circled in Figure 2. No security measures are assumed during this evacuation. Under the SO traffic assignment, $15.05 \%$ of the total number of vehicles used at least one of the circled links. For the UE case, $14.06 \%$ of the vehicles traveled at least one of these links, suggesting that for this particular scenario, UE traffic assignment is slightly safer that the SO assignment. This result is case specific and cannot be generalized to other scenarios or networks.

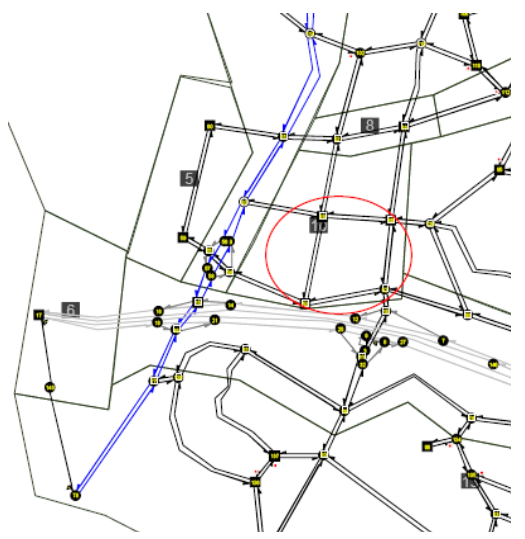

Figure 2: Location of Likely Secondary Targets

\subsection{Mobility}

Section 4.3 describes six measures of mobility. The simulation results for each measure are discussed in the subsections below.

\subsubsection{Evacuation Time}

The exact evacuation time depends on the definition of a completed evacuation. Figure 3 shows a comparison of the percentage of vehicles cleared at different times (keep in mind that the first 30 minutes establish background traffic).
If an evacuation is finished when less than $80 \%$ of the vehicles clear the network, differences between the SO and $\mathrm{UE}$ assignments are extremely small. At thresholds above $80 \%$, UE performs slightly better than SO until the threshold of $100 \%$ is approached.

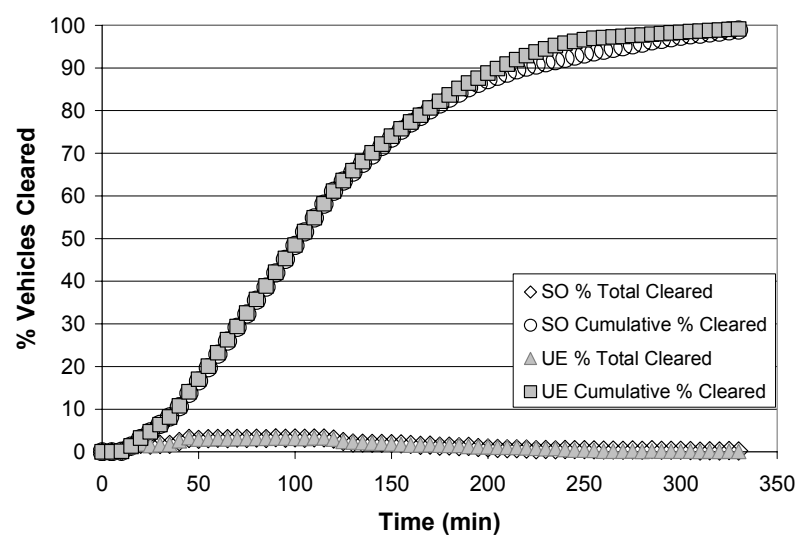

Figure 3: Network Clearance

\subsubsection{Response Vehicle Travel and Queuing Time}

The average response times for emergency vehicles among the Reston-based zones (i.e. through traffic origin zones are not considered) are determined by sending probe vehicles from one zone to another at different times during the simulation. Mean and standard deviation of both travel and queuing times are calculated over different vehicle start times, however, each start time under SO conditions corresponds to a start time under UE conditions. UE mean travel time is greater than SO mean response time for 58 $(64.4 \%)$ of the 90 zone combinations; UE's related standard deviation surpasses SO's in 48 (53.3\%) of the combinations. The UE average queuing time exceeds the $\mathrm{SO}$ average queuing time for $52(57.8 \%)$ of the zone combinations; the related standard deviation is higher in 50 cases (55.6\%). Thus, SO provides greater resiliency in the system's ability to address any secondary incidents or to help residents in other ways.

\subsubsection{Queue Length}

Queue length severity is examined through different thresholds for all of the freeway, highways, and major arterial links in the evacuation directions. Table 2 presents the maximum time that queues of different lengths exist.

The maximum queue length under SO conditions is 458.0 vehicles, while under the UE assignment, the maximum queue length is 464.4 vehicles (both for a 3.0 mile long link). Since the maximum queue is longer under UE conditions and Table 2 indicates that a greater amount of time is spent under the most severe queuing conditions, the SO assignment yields more mobility than UE, in terms of queue length. 
Table 2: Maximum Queue Durations

\begin{tabular}{ccc}
\hline $\begin{array}{c}\text { Queue Length } \\
\text { (vehicles) }\end{array}$ & $\begin{array}{c}\text { SO } \\
\text { Maximum } \\
\text { Amount of Time } \\
(\mathrm{min})\end{array}$ & $\begin{array}{c}\text { UE } \\
\text { Maximum } \\
\text { Amount of Time } \\
(\mathrm{min})\end{array}$ \\
\hline $10.1-25.0$ & 392 & 136 \\
$25.1-50.0$ & 140 & 305 \\
$50.1-75.0$ & 138 & 137 \\
$75.1-100.0$ & 58 & 110 \\
$100.1-125.0$ & 164 & 136 \\
$125.1-150.0$ & 52 & 43 \\
$150+$ & 289 & 305 \\
\hline
\end{tabular}

\subsubsection{Average Vehicle Queuing Time}

Closely related to the queue length measure, is vehicle queuing time, the average of which is calculated for Reston's residents. Table 3 presents this time as well as the average travel time. In light of Table 2's results, it is not surprising that Table 3 shows lower average queuing time. Thus, for both queuing measures, $\mathrm{SO}$ indicates greater mobility.

Table 3: Average Resident Queuing and Travel Time

\begin{tabular}{ccc}
\hline $\begin{array}{c}\text { Traffic } \\
\text { Assignment }\end{array}$ & $\begin{array}{c}\text { Average Queuing } \\
\text { Time among } \\
\text { Reston Residents } \\
\text { (min) }\end{array}$ & $\begin{array}{c}\text { Average Travel } \\
\text { Time among } \\
\text { Reston Residents } \\
\text { (min) }\end{array}$ \\
\hline SO & 46.64 & 66.77 \\
UE & 47.15 & 66.92 \\
\hline
\end{tabular}

\subsubsection{Link Speed}

The threshold selected for speed degradation is $10 \%$ below the posted speed limit. As in Section 5.3.3, this measure is applied to major links. Table 4 presents the top five links with the longest speed degradation duration for each assignment. Due to different routing under each traffic assignment, the links corresponding to the ranks in Table 4 are not necessarily the same. The UE assignment yields the maximum amount of time a link's speed is degraded. However, the magnitude of the differences among the top five links makes it difficult to draw any conclusions about which traffic assignment method results in greater mobility based on link speed.

Table 4: Amount of Time the Speed on the Top Five Links is Below $10 \%$ of the Speed Limit

\begin{tabular}{cccc}
\hline Rank & $\begin{array}{c}\text { SO }- \text { Time in } \\
\text { Deteriorated } \\
\text { State }(\min )\end{array}$ & $\begin{array}{c}\text { UE - Time in } \\
\text { Deteriorated } \\
\text { State }(\mathrm{min})\end{array}$ & $\begin{array}{c}\text { Difference } \\
\text { (SO-UE) }\end{array}$ \\
\hline 1 & 336 & 347 & -11 \\
2 & 309 & 322 & -13 \\
3 & 260 & 263 & -3 \\
4 & 257 & 211 & 46 \\
5 & 241 & 195 & 46 \\
\hline
\end{tabular}

\subsubsection{Volume/Capacity Ratio}

For the volume/capacity analysis, links are selected from among those comprising freeway, highway, and arterial roads, shown in Figure 1. The criterion for selection is the minimum amount of time under free flow conditions, based on the Highway Capacity Manual ratios. As noted in Section 5.3.5, variances in vehicle paths can lead to different links faring worse under the two assignments. In each case, the worst performing link of the major road is presented in Table 5.

Table 5: Percentage of the Planning Horizon that Major Roads are Within Different Volume/Capacity Thresholds

\begin{tabular}{|c|c|c|c|c|c|c|c|}
\hline \multirow{2}{*}{$\begin{array}{l}\text { Road- } \\
\text { way }\end{array}$} & & \multicolumn{6}{|c|}{ v/c Limit } \\
\hline & & 0.35 & 0.54 & 0.77 & 0.93 & 1.0 & $>1$ \\
\hline \multirow{2}{*}{$\begin{array}{c}\text { Freeway } \\
\text { Express } \\
\text { E-W }\end{array}$} & SO & 78.3 & 1.5 & 4.2 & 14.6 & 0.2 & 1.2 \\
\hline & UE & 77.5 & 1.0 & 2.1 & 16.0 & 0.4 & 2.9 \\
\hline \multirow{2}{*}{$\begin{array}{c}\text { Freeway } \\
\text { E-W }\end{array}$} & $\mathrm{SO}$ & 47.5 & 16.2 & 9.4 & 6.0 & 1.3 & 19.6 \\
\hline & UE & 51.9 & 11.2 & 5.8 & 6.5 & 2.5 & 22.1 \\
\hline \multirow{2}{*}{$\begin{array}{l}\text { Hwy } 1 \\
\text { SE-NW }\end{array}$} & SO & 74.0 & 5.6 & 11.5 & 9.0 & 0 & 0 \\
\hline & UE & 72.1 & 6.7 & 11.9 & 9.3 & 0 & 0 \\
\hline \multirow{2}{*}{$\begin{array}{l}\text { Hwy } 2 \\
\text { NE-SW }\end{array}$} & SO & 48.5 & 0.2 & 48.8 & 0.2 & 0.2 & 2.1 \\
\hline & UE & 54.8 & 0.4 & 42.7 & 0.4 & 0 & 1.7 \\
\hline \multirow{2}{*}{$\begin{array}{l}\text { Hwy } 2 \\
\text { SW-NE }\end{array}$} & $\mathrm{SO}$ & 43.8 & 0.2 & 47.9 & 1.7 & 0.8 & 5.6 \\
\hline & UE & 61.2 & 0.2 & 31.5 & 1.2 & 0.2 & 5.6 \\
\hline \multirow{2}{*}{$\begin{array}{c}\text { Arterial } \\
1 \mathrm{~S}-\mathrm{N}\end{array}$} & $\mathrm{SO}$ & 66.5 & 1.0 & 25.4 & 0.4 & 0.4 & 6.2 \\
\hline & UE & 53.3 & 0 & 39.8 & 0 & 0 & 6.9 \\
\hline \multirow{2}{*}{$\begin{array}{c}\text { Arterial } \\
1 \mathrm{~N}-\mathrm{S}\end{array}$} & SO & 29.8 & 0 & 32.1 & 18.5 & 0 & 19.6 \\
\hline & UE & 27.1 & 0 & 31.9 & 19.6 & 0.4 & 21.0 \\
\hline \multirow{2}{*}{$\begin{array}{c}\text { Arterial } \\
2 \mathrm{~S}-\mathrm{N}\end{array}$} & $\mathrm{SO}$ & 60.4 & 0.6 & 29.6 & 2.5 & 0.4 & 6.5 \\
\hline & UE & 60.8 & 1.0 & 11.7 & 16.0 & 0.8 & 9.6 \\
\hline \multirow{2}{*}{$\begin{array}{c}\text { Arterial } \\
2 \mathrm{~N}-\mathrm{S}\end{array}$} & SO & 79.4 & 0.6 & 15.6 & 0.6 & 0 & 3.8 \\
\hline & UE & 69.8 & 1.0 & 22.3 & 1.9 & 0.2 & 4.8 \\
\hline \multirow{2}{*}{$\begin{array}{c}\text { Arterial } \\
3 \mathrm{~S}-\mathrm{N}\end{array}$} & SO & 66.9 & 0.8 & 15.6 & 2.7 & 0.4 & 13.5 \\
\hline & UE & 68.1 & 1.9 & 0.8 & 0.8 & 0.2 & 28.1 \\
\hline \multirow{2}{*}{$\begin{array}{c}\text { Arterial } \\
3 \mathrm{~N}-\mathrm{S}\end{array}$} & SO & 66.9 & 7.5 & 3.8 & 1.5 & 3.3 & 17.1 \\
\hline & UE & 65.2 & 8.3 & 1.7 & 1.2 & 2.5 & 21.0 \\
\hline \multirow{2}{*}{$\begin{array}{c}\text { Arterial } \\
4 \mathrm{E}-\mathrm{W}\end{array}$} & $\mathrm{SO}$ & 70.4 & 0.6 & 21.0 & 0.6 & 0.2 & 7.1 \\
\hline & UE & 76.7 & 1.5 & 5.0 & 0.8 & 0.6 & 15.4 \\
\hline \multirow{2}{*}{$\begin{array}{c}\text { Arterial } \\
4 \mathrm{~W}-\mathrm{E}\end{array}$} & SO & 81.3 & 0.6 & 13.1 & 0.6 & 0.2 & 4.2 \\
\hline & UE & 79.8 & 0 & 14.2 & 1.2 & 0.6 & 4.2 \\
\hline \multirow{2}{*}{$\begin{array}{c}\text { Arterial } \\
5 \mathrm{E}-\mathrm{W}\end{array}$} & SO & 15.4 & 80.6 & 4.0 & 0 & 0 & 0 \\
\hline & UE & 10.8 & 67.3 & 3.8 & 2.7 & 0.4 & 15.0 \\
\hline \multirow{2}{*}{$\begin{array}{c}\text { Arterial } \\
5 \mathrm{~W}-\mathrm{E}\end{array}$} & $\mathrm{SO}$ & 31.5 & 1.0 & 60.2 & 0.8 & 0.2 & 6.3 \\
\hline & UE & 28.5 & 0.6 & 62.7 & 0.8 & 0.4 & 6.9 \\
\hline \multirow{2}{*}{$\begin{array}{l}\text { Arterial } \\
6 \mathrm{E}-\mathrm{W} \\
\end{array}$} & SO & 54.2 & 7.9 & 30.6 & 1.0 & 0.4 & 5.8 \\
\hline & UE & 68.1 & 3.5 & 24.4 & 1.0 & 0 & 2.9 \\
\hline \multirow{2}{*}{$\begin{array}{l}\text { Arterial } \\
6 \mathrm{~W}-\mathrm{E} \\
\end{array}$} & $\mathrm{SO}$ & 74.4 & 0.6 & 13.3 & 2.1 & 0.8 & 8.8 \\
\hline & UE & 68.5 & 0.6 & 22.5 & 1.2 & 0.2 & 6.9 \\
\hline
\end{tabular}


As shown in Table 5, neither assignment consistently yields a higher percentage of free flow conditions. Over all of the selected links, UE has the minimum amount of time under free flow conditions (arterial 5 westbound). SO conditions yield a higher percentage of free flow conditions for 10 of the 17 cases displayed in Table 5: the freeway express lanes, highway 1, arterial 1 in both directions, arterials 2 and 3 southbound, arterial 4 eastbound, arterial 5 in both directions, and arterial 6 eastbound. Thus, the SO assignment provides greater mobility, in terms of the amount of time in free flow conditions.

\subsection{Recovery}

In this study, three measures of congestion recovery are used: queue length, speed, and volume/capacity ratio. Each of these measures is discussed below with respect to the SO and UE traffic assignments.

In terms of queue length recovery $\left(t_{a}^{l}\right)$, the same thresholds as shown in Table 2 are used to determine the last time point at which a major link enters the queue length range (recovers from a greater queue length). As shown in Table 6, the UE assignment requires a later time point to recover to the indicated queue length range, thus indicating that SO yields a faster recovery.

Table 6: Queue Length Maximum Recovery Time Points

\begin{tabular}{ccc}
\hline $\begin{array}{c}\text { Queue Length } \\
\text { (vehicles) }\end{array}$ & SO & UE \\
\hline $10.1-25.0$ & 365 & $>480$ \\
$25.1-50.0$ & 361 & 373 \\
$50.1-75.0$ & 357 & 368 \\
$75.1-100.0$ & 353 & 364 \\
$100.1-125.0$ & 349 & 359 \\
$125.1-150.0$ & 344 & 355 \\
\hline
\end{tabular}

The second measure of recovery $\left(t_{a}{ }^{u}\right)$ is the time point at which the link speed returns to within $10 \%$ of the posted speed limit. The maximum recovery time point for speed is 380 for UE conditions and 370 for SO, again indicating that SO recovers faster than UE.

The final measure $\left(t_{a}{ }^{v}\right)$ is the maximum time point at which the selected links in Table 5 dip below the volume/capacity threshold. Table 7 presents the results over all of the selected links. These results support the other two recovery measures, thus SO recovers faster than UE.

Table 7: Volume/Capacity Maximum Recovery Time Points

\begin{tabular}{ccc}
\hline $\mathrm{v} / \mathrm{c}$ Limit & $\mathrm{SO}$ & $\mathrm{UE}$ \\
\hline 0.35 & $>480$ & $>480$ \\
0.54 & 370 & 382 \\
0.77 & 370 & 382 \\
0.93 & 370 & 382 \\
1.00 & 370 & 382 \\
\hline
\end{tabular}

\subsection{Results Summary}

This section and Table 8 summarize the relative performance of the traffic assignment methods for each resilience dimension and measure.

Table 8: Summary by Dimension and Measure

\begin{tabular}{l|c}
\hline \multicolumn{1}{c|}{ Dimension and Measure } & $\begin{array}{c}\text { Better Performing } \\
\text { Traffic Assignment }\end{array}$ \\
\hline Adaptability - use of special lanes & UE \\
\hline $\begin{array}{l}\text { Safety - exposure to traffic } \\
\text { accidents }\end{array}$ & UE \\
\hline $\begin{array}{l}\text { Safety - exposure to secondary } \\
\text { targets }\end{array}$ & UE \\
\hline Mobility - evacuation time & UE \\
\hline $\begin{array}{l}\text { Mobility - response vehicle travel } \\
\text { time }\end{array}$ & SO \\
\hline Mobility - link queue length & SO \\
\hline $\begin{array}{l}\text { Mobility - average vehicle } \\
\text { queuing time }\end{array}$ & SO \\
\hline Mobility - link speed & Inconclusive \\
\hline Mobility - volume/capacity ratio & SO \\
\hline Recovery - queue length & SO \\
\hline Recovery - link speed & SO \\
\hline Recovery - volume/capacity ratio & SO \\
\hline
\end{tabular}

The measures used in this study are not necessarily independent of one another. For example, a link's queue length can impede the travel time on that link. Therefore, although SO has better performance on more measures, it does not necessarily indicate greater resilience.

\section{CONCLUSIONS}

This paper provided several measures with which to evaluate four of the ten dimensions of transportation resilience. In conjunction with simulation, these measures were used to compare the system optimum and user equilibrium traffic assignments. In this study, user equilibrium performed slightly better in terms of adaptability and safety. However, in terms of the measure "exposure to secondary hazards," the results were specific to the sample network and cannot be generalized to any transportation system. System optimum performed better with respect to mobility and recovery from mobility degradation. The close performance of the two traffic assignment methods, in terms of resilience, is potentially network and demand scenario specific. Thus, the traffic assignment methodology should not be the only factor in assessing transportation resilience. The other six dimensions, redundancy, diversity, efficiency, autonomous components, strength, and collaboration, will play a large role in determining the system's resilience, though they are difficult to quantify. 
In the future, the measures presented in this paper will be combined with measures for the other six dimensions and additional metrics related to the four dimensions explored in this paper to form a comprehensive measure of resilience. Tradeoffs among the dimensions will be explicitly determined. Finally, the comprehensive resilience measure will address dependencies among the dimension level metrics.

Additionally, three future directions specific to the comparison of the SO and UE assignments will be explored. First, the sensitivity to measurement thresholds will be examined. Second, the traffic assignments will be compared for normal traffic conditions. Finally, a wide variety of networks and demand scenarios will be examined to determine whether SO and UE perform as closely as they did in this study.

\section{REFERENCES}

Allenby, B. and J. Fink. 2005. Toward inherently secure and resilient societies. Science 309 (5737): 10341036.

Buckle, I. 2005. Protecting critical infrastructure systems. Available via <http://www.caenz.com/info/2005Conf/ pres/Buckle.pdf $>$ [accessed April 26, 2006].

Chang, S.E. and C. Chamberlin. 2005. Assessing the role of lifeline systems in community disaster resilience. In Research Progress and Accomplishments 20032004, 87-94. Available via <http://mceer.buffalo.edu/ publications/resaccom/04-SP01/07_Chang.pdf $>$ [accessed April 26, 2006].

Cohen, R., K. Erez, D. Ben-Avraham, and S. Havlin. 2000. Resilience of the Internet to Random Breakdowns. Physical Review Letters 85(21): 4626-4628.

Dolev, D., S. Jamin, O. Mokryn, and Y. Shavitt. c. 2004. Internet resiliency to attacks and failures under BGP policy routing. Available via <http://www.eng.tau. ac.i1/ osnaty/pub/res.pdf $>$ [accessed March 16, 2005].

Foster, H.D. 1997. The Ozymandias principles: thirty-one strategies for surviving change. Victoria: Southdowne Press.

Godschalk, D.R. 2002. Urban hazard mitigation: creating resilient cities. Available via $<$ www.arch.columbia. edu/Studio/Spring2003/UP/Accra/links/Godshalk ResilientCities.doc $>$ [accessed April 26, 2006].

Mileti, D.S. 1999. Disasters by Design: A Reassessment of Natural Hazards in the United States. Joseph Henry Press. Available via <http://darwin.nap.edu/books/ 0309063604/html/> [accessed April 10, 2006].

Morlok, E.K. and D.J. Chang. 2004. Measuring capacity flexibility of a transportation system. Transportation Research Part A 38(6): 405-420.

Murray-Tuite, P.M. and H.S. Mahmassani. 2004. Methodology for the determination of vulnerable links in a transportation network. Transportation Research Record 1882: 88-96.

National Center for Statistics \& Analysis. c. 2005. Fatality analysis reporting system web-based encyclopedia. Available via <http://www-fars.nhtsa.dot.gov/finalre port.cfm?title $=$ States $\&$ stateid $=0 \&$ year $=2004 \&$ title $2=\mathrm{F}$ atalities_and_Fatality_Rates $>$ [accessed June 14, 2006].

Shinozuka, M., et al. 2005. Resilience of Integrated Power and Water Systems. In Research Progress and Accomplishments 2003-2004, 65-86. Available via $<$ http://mceer.buffalo.edu/publications/resaccom/04SP01/06_shino.pdf>

[accessed April 26, 2006].

Subcommittee on Disaster Reduction. 2005. Grand Challenges for Disaster Reduction. Washington, D.C.: Executive Office of the President of the United States. Available via < http://www.sdr.gov/SDRGrand ChallengesforDisasterReduction.pdf $>$ [accessed April 27, 2006].

U.S. Census Bureau. 2000. Profile of general demographic characteristics: 2000 geographic area: Reston CDP Virginia. Available via <http://censtats.census. gov/data/VA/1605166672.pdf $>$ [accessed April 26, 2006].

Victoria Transport Policy Institute. 2005. Evaluating transportation resilience. In TDM Encyclopedia. Available via <http://www.vtpi.org/tdm/tdm88.htm> [accessed April 27, 2006].

Werner, S.D., et al. 2005. New Developments in Seismic Risk Analysis of Highway Systems. In Research Progress and Accomplishments 2003-2004: 221-238. Available via <http://mceer.buffalo.edu/publications/ resaccom/04-sp01/15_werner.pdf $>$ [accessed April 26, 2006].

\section{AUTHOR BIOGRAPHY}

PAMELA M. MURRAY-TUITE is an Assistant Professor of Civil and Environmental Engineering at Virginia Polytechnic Institute and State University (Virginia Tech). She was previously a senior consultant with Booz Allen Hamilton. She received a BS degree in Civil Engineering from Duke University and an MS and a PhD in Civil Engineering from The University of Texas at Austin. Her current research interests focus on transportation network analysis, modeling, and simulation; security, reliability, risk, and resilience analysis; evacuation modeling; disaster recovery modeling; and congestion mitigation. Her e-mail address is<murraytu@vt.edu>. 